\title{
Synergistic effects of fishing-induced demographic changes and climate variation on fish population dynamics
}

\author{
M. Hidalgo ${ }^{1, *, * *}$, T. Rouyer ${ }^{1, * *}$, J. C. Molinero ${ }^{2}$, E. Massutí ${ }^{3}$, J. Moranta ${ }^{3}$, B. Guijarro ${ }^{3}$, \\ N. Chr. Stenseth ${ }^{1,4}$ \\ ${ }^{1}$ Centre for Ecological and Evolutionary Synthesis (CEES), Department of Biology, University of Oslo, PO Box 1066 Blindern, \\ 0316 Oslo, Norway \\ ${ }^{2}$ Leibniz-Institut für Meereswissenschaften, IFM-GEOMAR, FB3-Marine Ecology/Experimental Ecology, \\ Düsternbrooker Weg 20, 24105 Kiel, Germany \\ ${ }^{3}$ Instituto Español de Oceanografía, Centre Oceanografic de Balears, Moll de Ponent s/n, 07015 Palma de Mallorca, Spain \\ ${ }^{4}$ Institute of Marine Research, Flødevigen Marine Research Station, 4817 His, Norway
}

\begin{abstract}
The synergistic effects of fishing, climate and internal dynamics on population fluctuations are poorly understood due to the complexity of these interactions. In this paper, we combine time series analysis and simulations to investigate the long-term dynamics of an overexploited population in the Mediterranean Sea, and its link with both fishing-induced demographic changes and hydroclimatic variability. We show that the cyclicity of the catch per unit of effort (CPUE) of European hake Merluccius merluccius (EH) vanished in the 1980s, while the correlation between the CPUE and a local environmental index increased. Using simulations, we then show that the cyclicity observed in the EH biomass before the 1980s can have an internal origin, while that its disappearance could be due to the fishinginduced erosion of the age structure. Our results suggest that fishing can trigger a switch from internally generated to externally forced population fluctuations, the latter being characterised by an increasing dependency of the population on recruitment and ultimately on environmental variability. Hydroclimatic modifications occurring in the Mediterranean in the early 1980s could have enhanced these changes by leading to a mismatch between early life stages of EH and favorable environmental conditions. Our conclusions underline the key effect of the interaction between exploitation and climate on the dynamics of $\mathrm{EH}$ and its important consequences for management and conservation.
\end{abstract}

KEY WORDS: Demographic truncation - Fish population dynamics · Synergistic effects climate-fishing • European hake $\cdot$ Mediterranean climate

Resale or republication not permitted without written consent of the publisher

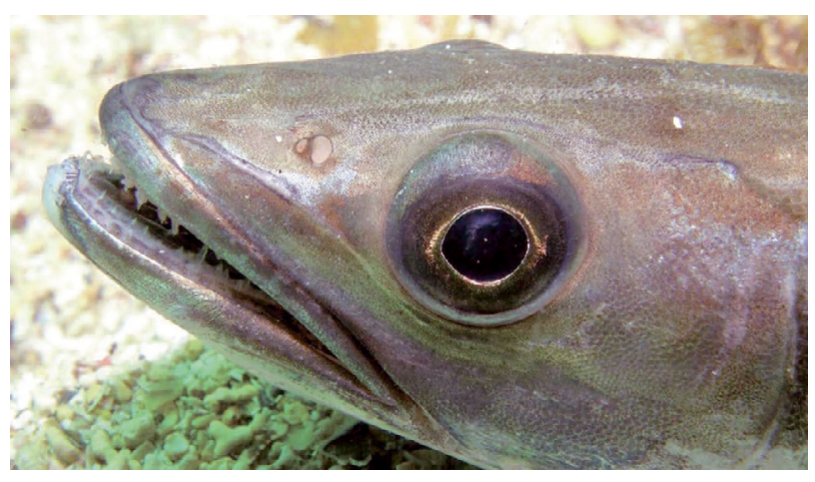

Fishery-induced modification of the demography of European hake Merluccius merluccius has led to a shift towards recruitment-dependent population dynamics.

Image: Jorge Hernandez (IEO)

\section{INTRODUCTION}

For a long time, downward trends in fish population abundances were mainly interpreted as a consequence of fishing exploitation, while environmental forcing was mainly seen as additive noise. However, recent research shows that the effects of these external forces on the exploited populations are interactive rather than additive (Kirby et al. 2009, Perry et al. 2010, Planque et al. 2010). Improving the scientific basis for a sustainable management of marine resources therefore requires understanding the consequences of the synergisms between climate and fishing on the sizes of exploited populations - a central challenge for fisheries ecology (Anderson et al. 2008, Rouyer et al. 2008). 
The response of harvested populations to external forces (i.e. climate variation and fishing) ranges from observable changes in demographic parameters, such as life span and population growth rate (e.g. Anderson et al. 2008), to hidden evolutionary modifications in life history traits (e.g. Jørgensen et al. 2007). Such changes can alter the resistance and resilience of fish populations to adverse environmental conditions and exploitation (Hutchings \& Reynolds 2004, Hsieh et al. 2006, Walsh et al. 2006, Perry et al. 2010, Planque et al. 2010). In particular, the ability to buffer the effects of external forces is largely due to the population's age structure and the species' life history traits. For example, populations with several reproductive age classes (e.g. cod) are more likely to withstand prolonged periods of adverse conditions for reproduction than species with only a few classes (e.g. sardine). Also, such populations often display bet-hedging strategies (e.g. age-related differences in spawning location and time), which buffer the stochastic spatiotemporal variations in the environment and stabilise population fluctuations (Hsieh et al. 2010). Finally, greater fecundity and larger egg size at older ages increase the offspring fitness (i.e. maternal effects), which has been demonstrated for various stocks and species (e.g. Berkeley et al. 2004a,b). In consequence, fishing might alter the ability of populations to buffer the effects of external forces through the sizeselective harvesting of larger and older individuals (Ottersen et al. 2006, Anderson et al. 2008, Ottersen 2008, Stenseth \& Rouyer 2008).

In addition to these biological effects, a broad demographic structure enables recruitment to spread among age classes, which can generate cycles in the population size due to the autocovariance between cohorts (Fromentin \& Fonteneau 2001) and inter- or intracohort interactions (e.g. 'cohort-resonance effect', Bjørnstad et al. 1999, 2004). Size-selective harvesting therefore results in fish populations being more dependent on the abundance of the younger age classes. This can consequently tighten the link between population dynamics and recruitment strength and, ultimately, with environmental variability (but see Brunel 2010), with a subsequent effect on population fluctuations (Hsieh et al. 2006, Anderson et al. 2008). As a consequence, the dominance of young age classes implies both a lesser ability to buffer environmental changes per se and lower reproductive success by undermining bet-hedging strategies and maternal effects.

In the present study, we examined the interaction between climate variability and fishing, using data of an overexploited groundfish species-the population of European hake Merluccius merluccius (EH) from the Balearic Sea in the Northwestern Mediterranean Sea (Fig. 1). Previous investigations reported 2 major changes in the inter-annual variability of population abundance in $\mathrm{EH}$, in 1980 and 1995, and attributed them to the long-term exploitation of this species (Hidalgo et al. 2009a). Mediterranean fisheries are known for their long-term harvesting of juveniles, with $\mathrm{EH}$ being the most representative species showing this exploitation pattern (Caddy 1993). In addition to the effects of exploitation, a close link between Mediterranean hydroclimatic variability and plankton communities has been reported in the western Mediterranean (Molinero et al. 2005, Fernández de Puelles \& Molinero 2007, 2008). This might affect the dynamics in species (such as EH) of the higher trophic levels through reduced availability of prey (i.e. zooplankton) for the early life stages of fish and/or shifts in the seasonal match between prey and predators. In the present study, we investigated the changes in the periodicity of the variability of the catch per unit effort (CPUE) time series and the changes in the association of this variability with the environment. Then, using a simple age-structured model, we explored whether all these changes could have been caused by fishing-induced demographic changes.

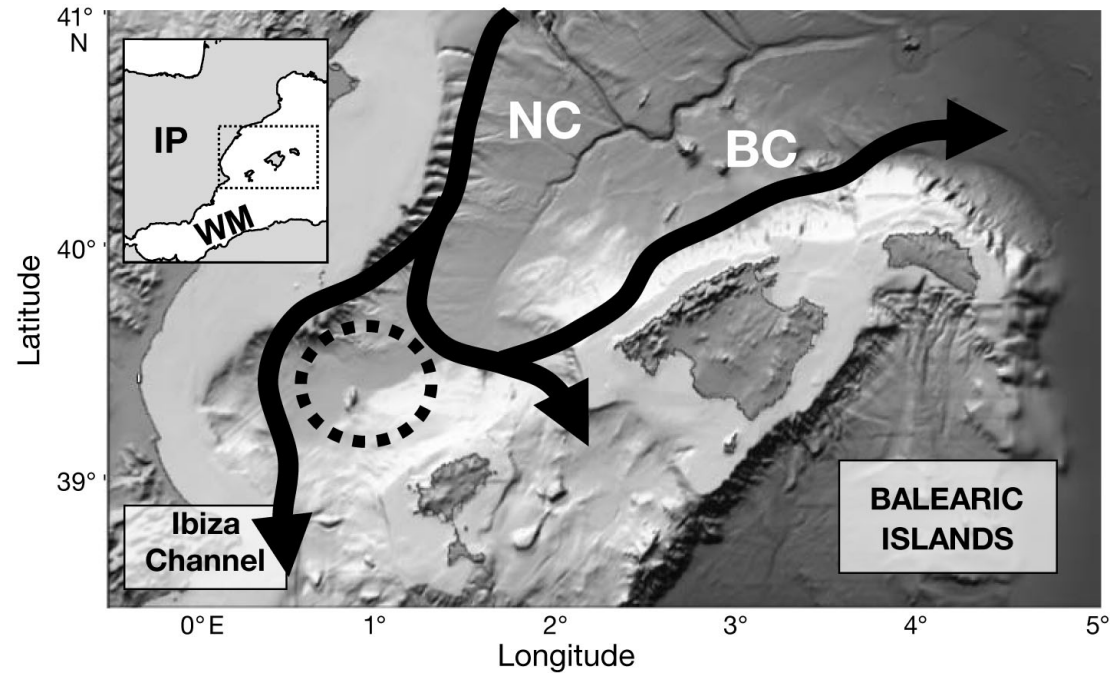

Fig. 1. Balearic Sea in the NW Mediterranean, showing Northern (NC) and Balearic (BC) slope currents. The NC flows southward reaching the Ibiza channel, where it bifurcates into 2 branches. One branch continues southward and the other forms the $\mathrm{BC}$, which flows towards the northeast along the northwestern slope of the Balearic Islands. Mesoscale structures (dashed circle) in the Ibiza channel determine the degree of bifurcation each year, and affect the annual oceanographic regime (IDEA index; more details in the 'Materials and methods' section and in Monserrat et al. 2008). IP: Iberian peninsula, WM: western Mediterranean Sea 


\section{MATERIALS AND METHODS}

Biological data. CPUE $\left(g \mathrm{hp}^{-1} \mathrm{~d}^{-1}, \mathrm{hp}=\right.$ horsepower $)$ time series were used as an index of population biomass (1940 to 2007). The effort used to standardise CPUE accounted for the engine power per vessel, number of vessels and days of fishing within a year. Effort estimates displayed a constant upward trend from 1940 to the early 1990s, after which they began a downward trend. Fluctuations in CPUE are independent of the trawl effort (Oliver 1993) and consistently represent the dynamics in the EH population (Massutí et al. 2008, Hidalgo et al. 2009a).

Climate indices. A mesoscale (regional) hydroclimatic index (IDEA index) based on the air/sea heat fluxes in the Gulf of Lion during winter months was used as a proxy for the strength of the current in the northwest Mediterranean Sea (Monserrat et al. 2008). This index is calculated using standardised observed air temperature in winter. Lower values of the IDEA index indicate a larger formation of Western Mediterranean Intermediate Waters (WIW) in winter at intermediate layers (100 to $300 \mathrm{~m}$ depth) in the Gulf of Lion; this implies a larger presence of these water masses in the Balearic Sea during spring. WIW are associated with an increase in productivity in late winter and spring, and have a positive effect on EH recruitment (Hidalgo et al. 2008, Massutí et al. 2008).

Seasonal climatic pattern. We investigated whether changes in the seasonal pattern of the hydroclimatic conditions in the Balearic Sea were associated with the variability in regional climate indices and the $\mathrm{EH}$ biomass index. A successful match between the early life stages and favourable environmental conditions has a strong positive effect on the persistence of $\mathrm{EH}$ (Hidalgo et al. 2009b). To summarise regional hydroclimatic variability, we used monthly anomaly fields of the following parameters: surface air temperature, sea surface temperature, atmospheric sea level pressure, $500 \mathrm{hPa}$ geopotential height and precipitation records, for the period 1950 to 2007 from the NCEP/NCAR reanalysis fields (Kalnay et al. 1996, see Molinero et al. 2005 for details). Inter-annual variations in the main signal of the seasonal hydroclimatology in the Balearic Sea was assessed using principal component analysis (PCA) applied to monthly time series of the aforementioned regional atmospheric variables. To detect years with similar seasonal patterns, a cluster analysis was applied to monthly values in a matrix of 59 by 12 (i.e. years by months) of the first principal component of the PCA ( $66 \%$ of the total variance). The Bray-Curtis similarity index was chosen as the similarity coefficient and group average was used as the clustering algorithm (Clarke \& Warwick 1994).
Time series analyses. Non-stationarity is the rule rather than the exception in ecology. We therefore used wavelet analysis (Cazelles et al. 2008) to investigate the fluctuations of both the $\mathrm{EH}$ population biomass and the environmental time series. The wavelet transform is a technique that allows for the decomposition of the variance over a time/frequency diagram. The analysis involves a mathematical function (the mother wavelet) that is dilated and translated (the daughter wavelets), to ultimately be compared with the time series. For a given set of parameters $a$ (scale/dilation parameter related to frequencies) and $\tau$ (translation parameter related to time position), the wavelet function $\psi$ is defined at time $t$ as follows:

$$
\psi_{a, \tau}(t)=\frac{1}{\sqrt{a}} \psi\left(\frac{t-\tau}{a}\right)
$$

As these functions are local, they allow for the detection of dates at which changes of behaviour occur in the time series. The wavelet transform $W$ of the time series $x$ is obtained by the convolution product between the wavelets and the time series:

$$
W_{x}(a, \tau)=\frac{1}{\sqrt{(a)}} \int x(t) \psi\left(\frac{t-\tau}{a}\right) \mathrm{d} t=\int x(t) \psi_{a, \tau} \mathrm{d} t
$$

In the following analyses, we used the Morlet wavelet, a continuous and complex wavelet with a simple link to frequencies and adapted to wave-like signals (e.g. Menard et al. 2007, Cazelles et al. 2008, Rouyer et al. 2008). The wavelet power spectrum $S$ for the time series $x$ is then defined as:

$$
S_{x}(a, \tau)=\left|W_{x}(a, \tau)\right|^{2}
$$

$S$ is represented on a 2 D time/frequency plot with the intensity of the variance at each time/frequency occurrence being represented on a colour scale ranging from blue (low variance) to dark red (high variance). To describe the variability of the signal through time (i.e. periods when the major shifts occurred), univariate wavelet spectra were investigated for the biomass index of EH in the Balearic Sea (i.e. CPUE) and the IDEA climatic index.

Population dynamics simulations. We used a simple and classical population model to investigate the consequences of an age-selective removal under different scenarios of climate forcing. The simulations were performed using the following stochastic age-structured model based on the fundamental equation of fish stock dynamics:

$$
N_{i, t}=N_{i-1, t-1} \mathrm{e}^{-\left(M_{i-1, t}+F_{i-1, t}\right)}
$$

where $N_{i, t}$ is the number of age $i$ fishes at time $t$, and $M_{i, t}$ and $F_{i, t}$ are, respectively, the natural mortality and the fishing mortality for age $i$ at time $t$. The natural mortality vector $\left(M_{0}=1.3, M_{1}=0.8, M_{2}=0.4, M_{3}=0.3\right.$ 
and $M_{4+}=0.2$ ) was obtained from previous estimations of a nearby Mediterranean population (Ligurian Sea; Caddy \& Abella 1999, Bartolino 2008). The fishing mortality vector (Fig. 2a) was obtained from population models for the assessment of the species in the Balearic Islands region (FAO-GFCM 2008), which showed the intensive exploitation of juvenile EH characteristic of Mediterranean demersal populations (Caddy 1993, Lleonart \& Maynou 2003). The increase in effort was simulated by an increase following a logistic curve, so that the fishing mortality was 0 at the beginning of the simulation and increased until reaching 3 times the initial values of the fishing mortality vector (Fig. 2b), hence mimicking the observed increase in the empirical data (Fig. 3a). The maximum age was set at 11 yr (FAOGFCM 2008). The maturity ogive was set equal to the following vector: $\mathrm{Mat}_{0}=0, \mathrm{Mat}_{1}=0.4, \mathrm{Mat}_{2}=0.4$, $\mathrm{Mat}_{3}=0.4, \mathrm{Mat}_{4}=0.5, \mathrm{Mat}_{5}=0.7$, $\mathrm{Mat}_{6+}=1$, where Mat ${ }_{i}$ is the probability of an individual maturing at age $i$ (FAO-GFCM 2008). The size at age $i$ $\left(L_{i}\right)$ was obtained using the von Bertalanffy growth curve:

$$
L_{i}=L_{\infty}\left(1-\mathrm{e}^{-k\left(i-T_{0}\right)}\right)
$$

with $L_{\infty}=85 \mathrm{~cm}$ the asymptotic growth, $k=0.17$ the growth coefficient and $T_{0}=-0.18$ the adjustment factor (FAO-GFCM 2008).

The conversion between size at age and weight at age $\left(W_{i}\right)$ was done according to the following relationship:

$$
W_{i}=a L_{i}^{b}
$$

with $a=0.0048$ and $b=3.12$ (FAOGFCM 2008).

The age-structured model was forced by a stochastic Ricker curve, which has previously been fitted to observational data (recruitment and spawning stock biomass, Massutí et al. 2008):

$$
R_{t}=\alpha \mathrm{SSB}_{\mathrm{t}-1} \mathrm{e}^{\beta \mathrm{SSB}_{t-1} \gamma \varepsilon_{t}}
$$

where $R_{t}$ is the recruitment (number of fish which grow into age
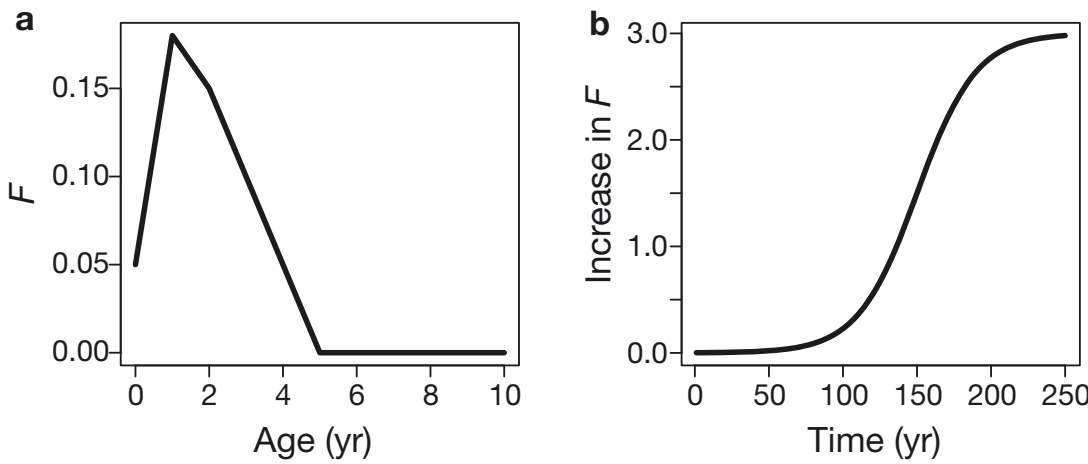

Fig. 2. (a) Mean fishing mortality vector $(F)$ used in the simulations and (b) evolution of fishing mortality over time
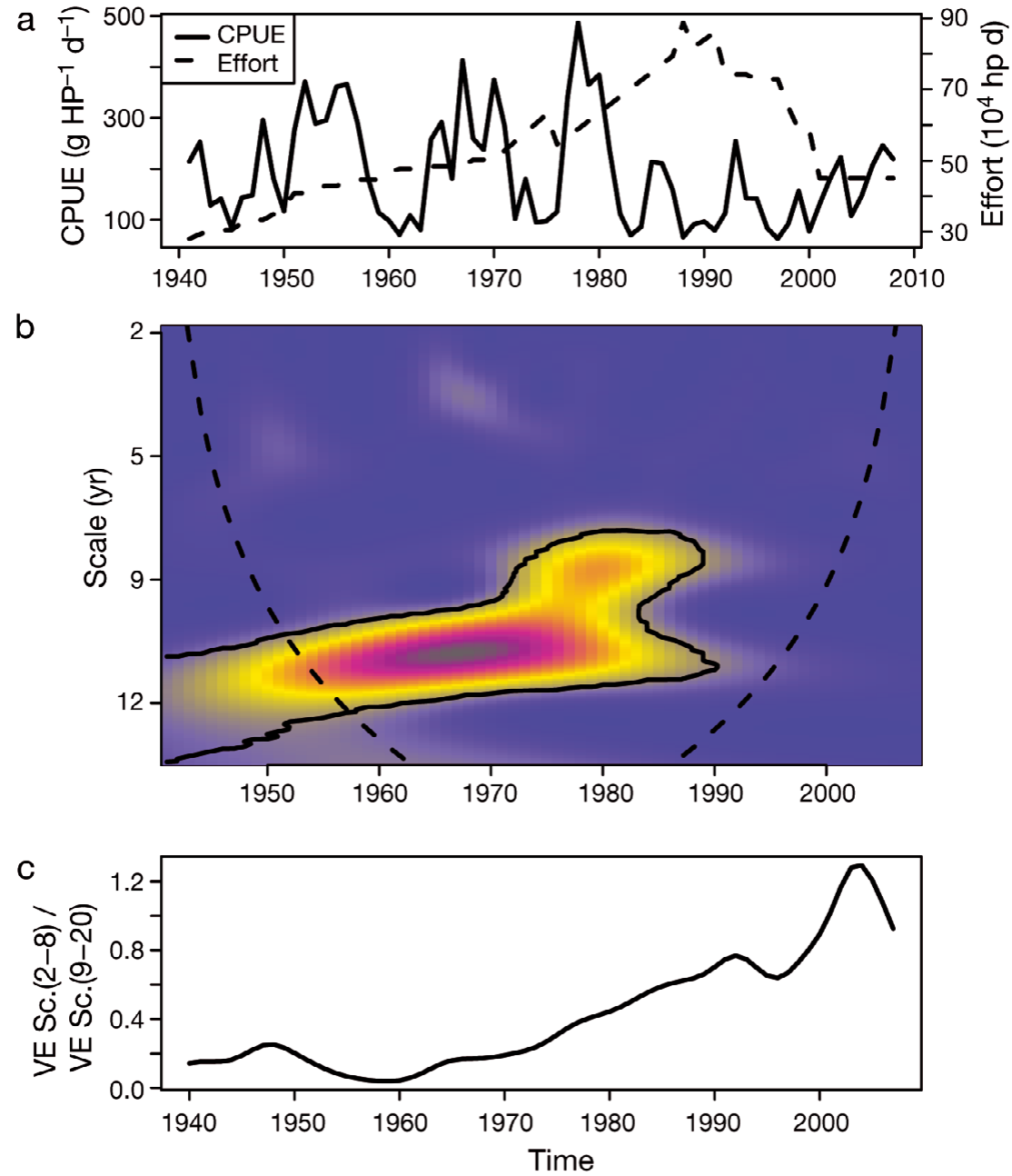

Fig. 3. (a) Catch per unit effort (CPUE, $g \mathrm{hp}^{-1} \mathrm{~d}^{-1}$ ) of European hake and fishing effort $\left(10^{4} \mathrm{hp} \mathrm{d}\right)$. (b) Univariate wavelets spectrum of the CPUE. The wavelet spectrum decomposes the variance of time series over time ( $x$-axis) and periods ( $y$-axis), revealing the time evolution of the relative importance of modes (periodicities) in the signal. The colour gradient, from dark blue through dark red to grey codes for low- to high-power values. Solid black lines indicate significant areas at the $5 \%$ level. Curved dashed lines display the limit of the cone of influence, the area where edge effects are present. (c) Ratio between the variance explained (VE) by high frequencies ( 2 to $8 \mathrm{yr}$, short time scales) and low frequencies (9 to $20 \mathrm{yr}$, long time scales). Sc. $=$ scale 
class 0 the first year of life) at time $t$, SSB is the spawning stock biomass, and $\varepsilon$ is a stochastic environment. $\alpha, \beta$ and $\gamma$ parameters were taken from Massutí et al. (2008), where $\alpha=175.81, \beta=-0.043$ and $\gamma=-0.422$. This model explained $46 \%$ of the variance.

Two environmental scenarios were investigated $(\varepsilon$, stochastic environment) for recruitment: (1) white noise (balancedvariance mix of low and high frequencies) was used as a control experiment, and (2) red noise, which is characterised by a dominance of low frequencies in the signal, was used as a more realistic environmental scenario (Vasseur \& Yodzis 2004) consistent with the IDEA index that drives recruitment (Massutí et al. 2008). For the 2 scenarios, the total variance of the environmental signal was calibrated on the variance of the environmental signal used for the fit of the recruitment curve of Massutí et al. (2008). Simulations were run over $250 \mathrm{yr}$ (Fig. 2b). The procedure was repeated 1000 times, and the demographic variables (recruits, abundance and biomass) were obtained by extracting the mode of the distribution for all simulations. The total biomass yielded by the model was analysed using wavelets to track the evolution of the variance of the signal over time. We investigated the evolution of the link of the total biomass and the recruitment with the environment by computing their correlations over time, while we tracked the mean age in the population over time.

\section{RESULTS}

\section{Time series analyses}

The time series of EH CPUE displayed fluctuations that increased in frequency over time and decreased in amplitude, while the effort was gradually increasing (Fig. 3a). From 1940 to 1980, the wavelet spectrum of the CPUE displayed a significant cyclicity around 12 yr which disappeared after 1980 (Fig. 3b). The mean scale of fluctuations displayed a constant decrease over time from an average of $12 \mathrm{yr}$ over the period 1940 to 1980, to 9 yr after 1980 (Fig. 3b). The increasing frequency through the last 3 decades (i.e. 1980 s, 1990s, 2000s) was confirmed by the ratio between the mean variance of the short ( 2 to $8 \mathrm{yr}$ ) and the large (>9 yr) time scales (Fig. 3c).
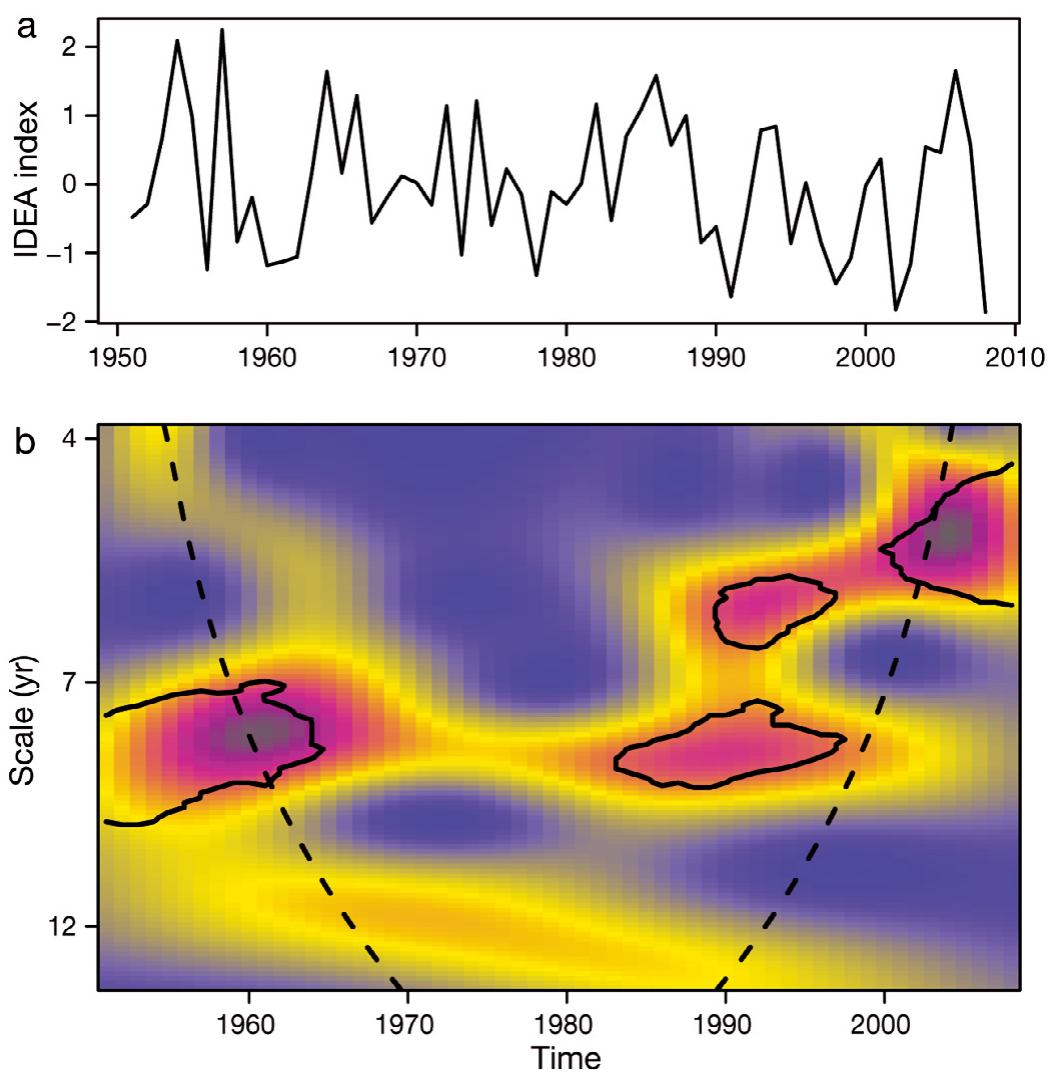

Fig. 4. (a) Time series of the IDEA index analysed from 1950 to 2007. (b) Univariate wavelet spectra of the IDEA index. The colour gradient, from dark blue through dark red to grey, codes for low- to high-power values. Solid black lines indicate significant areas at the $5 \%$ level. Curved dashed lines display the limit of the cone of influence, the area where edge effects are present

The environmental series also displayed a change in behaviour in the 1980s. The IDEA index did not display any clear periodicity before the 1980s (Fig. 4a), while a 6 and $9 \mathrm{yr}$ pattern emerged in the early 1980s (Fig. 4b). PCA analysis revealed a change in the regional hydroclimatic variability in the Balearic Sea in the early 1980s (PC1, 66\% of the total variance, Fig. 5a). The cumulative sum showed that the mostly change occurred in 1980 (Fig. 5a), which was mainly related to a change in the winter conditions (Fig. 5b).

To follow potential changes in the link between abundance and environment, we computed the correlation between the CPUE and the IDEA index over a moving window. The size of the window was set at $20 \mathrm{yr}$ to be consistent with the time scale of events, while we adjusted the number of degrees of freedom to account for autocorrelation (see Pyper \& Peterman 1998). The time series of the correlations showed a general increase over time contemporary to the change in behaviour of the CPUE (Fig. 6). The correlations were statistically non significant and relatively weak until the late 1970 s then shifted to become stronger and significant. 
a
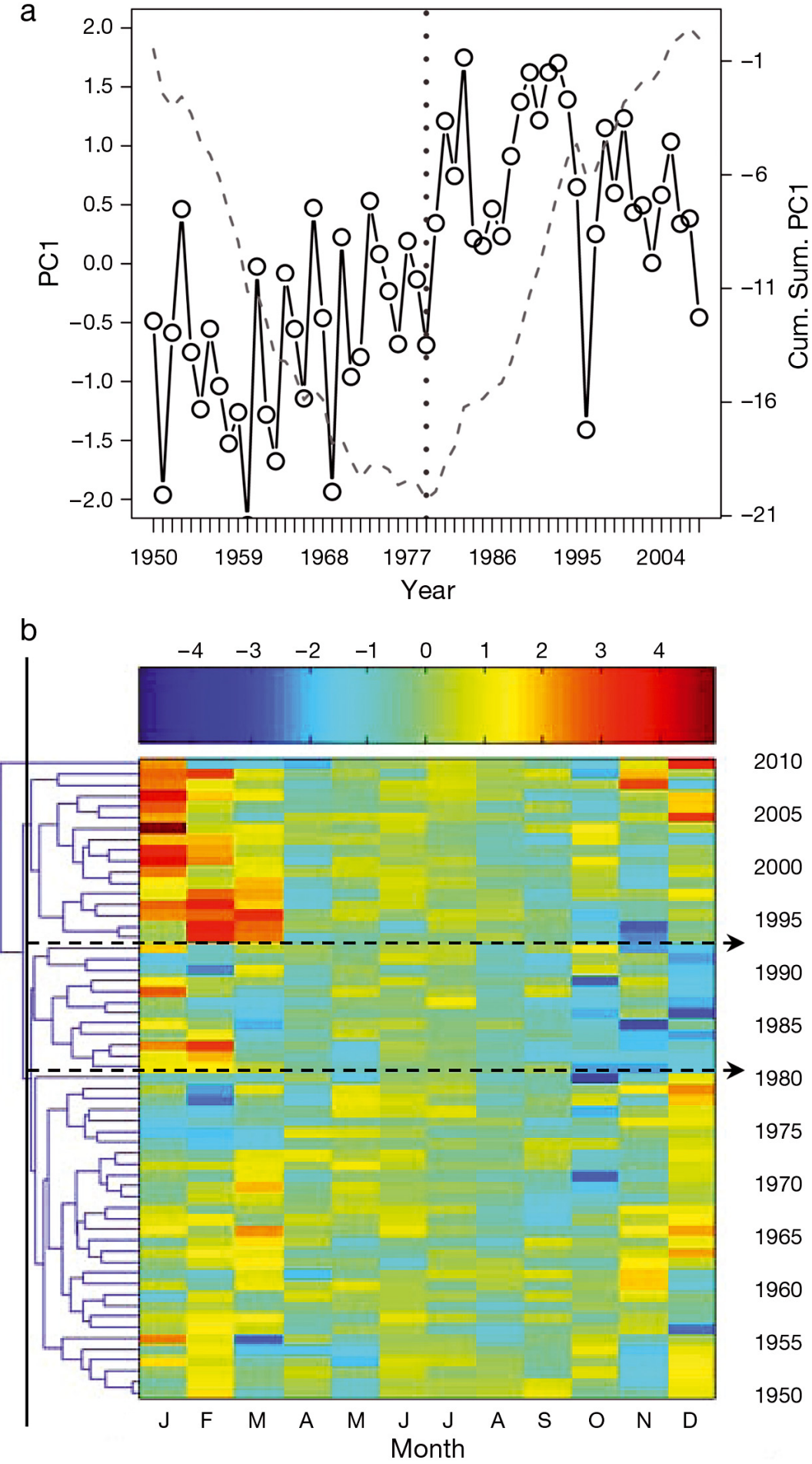

Fig. 5. (a) Annual average (solid black line) of the monthly values of the first principal component of the principal component analysis (PCA) from 1950 to 2008 (which explained $66 \%$ of the variance) and the cumulated sums (dashed grey line), showing the main change occurring in the early 1980s (vertical dotted line). (b) Monthly values of the first principal component of the PCA. Low values are indicated in blue while high values are in red. A cluster analysis applied and shown on the left of the panel segregates 3 periods: 1950-1980, 1981-1993 and 1994-2008, as denoted by the solid black line within the cluster, and delimited by the dashed horizontal lines

\section{Population dynamics simulations}

The simulated dynamics stabilised after $50 \mathrm{yr}$, and these early years were discarded from the analyses. In the absence of fishing, the simulated population biomass displayed a cyclicity characterised by a $15 \mathrm{yr}$ period for both the red noise (Fig. $7 a, b$ ) and the white noise (see Fig. S1a,b in the Supplement at www.int-res.com/articles/suppl/m426 p001_supp.pdf) environments. This periodicity was consistent with that observed in the CPUE time series before the 1980s (Fig. 3b). No consistent increase in the relative importance of the high frequencies was detected (Figs. 7c \& S1c in the Supplement), and no difference was found between the 2 environmental scenarios, except in the amplitude of the cycles produced by the model.

When fishing was included, the simulated biomass for the red noise environment still displayed a signal dominated by a $15 \mathrm{yr}$ period, which progressively disappeared as the effort was increasing (Fig. 7d,e). Again, the same results were found for the white noise scenario (Fig. S1d,e in the Supplement). Contemporaneously to the increase in effort, the simulations displayed an increase in the relative importance of the high frequencies in the signal (Figs. $7 \mathrm{f} \&$ S1f in the Supplement). In addition to the loss of cyclicity, a sharp decline in variance was detected for the 2 simulated environments (Figs. 7d \& S1d in the Supplement), consistent with the decrease in variance observed in the CPUE estimates (Fig. 3a).

The implications of such changes are 2-fold. First, they reflect an increasing relative importance of recruitment to the total biomass, and second, an increased importance of environmental variability to population size. As a consequence of exploitation, the structure of the population no longer allowed for the building of intrinsic fluctuations (i.e. the $15 \mathrm{yr}$ cycle), and biomass fluctuations appeared shaped by environmental forcing through recruitment. This was confirmed by the relative stability of the mean age and the percentage of recruitment into the overall population over time in the ab- 


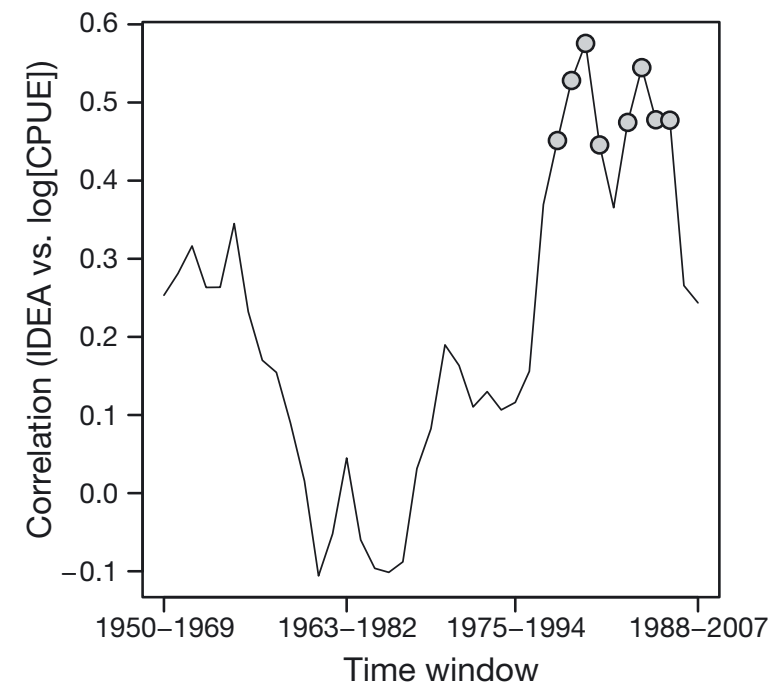

Fig. 6. 20 yr moving-window correlation between $\log$ (catch per unit effort, CPUE) and the IDEA index. Grey dots indicate significant $(\mathrm{p}<0.05)$ correlation coefficients

sence of fishing (Fig. 8a, and see Fig. S2a in the Supplement). Such long-term stability was also found in the correlation between the total biomass and the environment, and between recruitment and the environment for the red noise (Fig. 8b,c) and white noise (Fig. S2b,c in the Supplement) scenarios. When fishing was introduced, the contribution of recruitment into the population increased while the mean age decreased (Figs. 8d \& S2d in the Supplement). The correlation between biomass and the environment increased from 0 to 0.3 as effort increased (Figs. 8e \& S2e in the Supplement), while the correlation between recruitment and the environment increased from 0.6 to 0.9 (Figs. 8f \& S2f in the Supplement).

\section{DISCUSSION}

Fishing-induced demographic changes have been recognised as a key factor to understand how exploitation can impact the natural fluctuations of populations (Longhurst 1998, Beamish et al. 2006). However, evidence is growing that the interactions between exploitation and climate need to be considered to implement sound management (Rouyer et al. 2008, Kirby et al. 2009, Perry et al. 2010, Planque et al. 2010). Recent studies (i.e. Hsieh et al. 2006, Anderson et al. 2008) show that the variability in population abundances can be higher for harvested stocks due to changing demographic parameters, i.e. intrinsic growth rate, which enhance the non-linear dynamics of populations. Our results show that the variability can also be modified qualitatively by the change in demographic structure. Using the case study of a commercially targeted species in the Mediterranean, we have shown
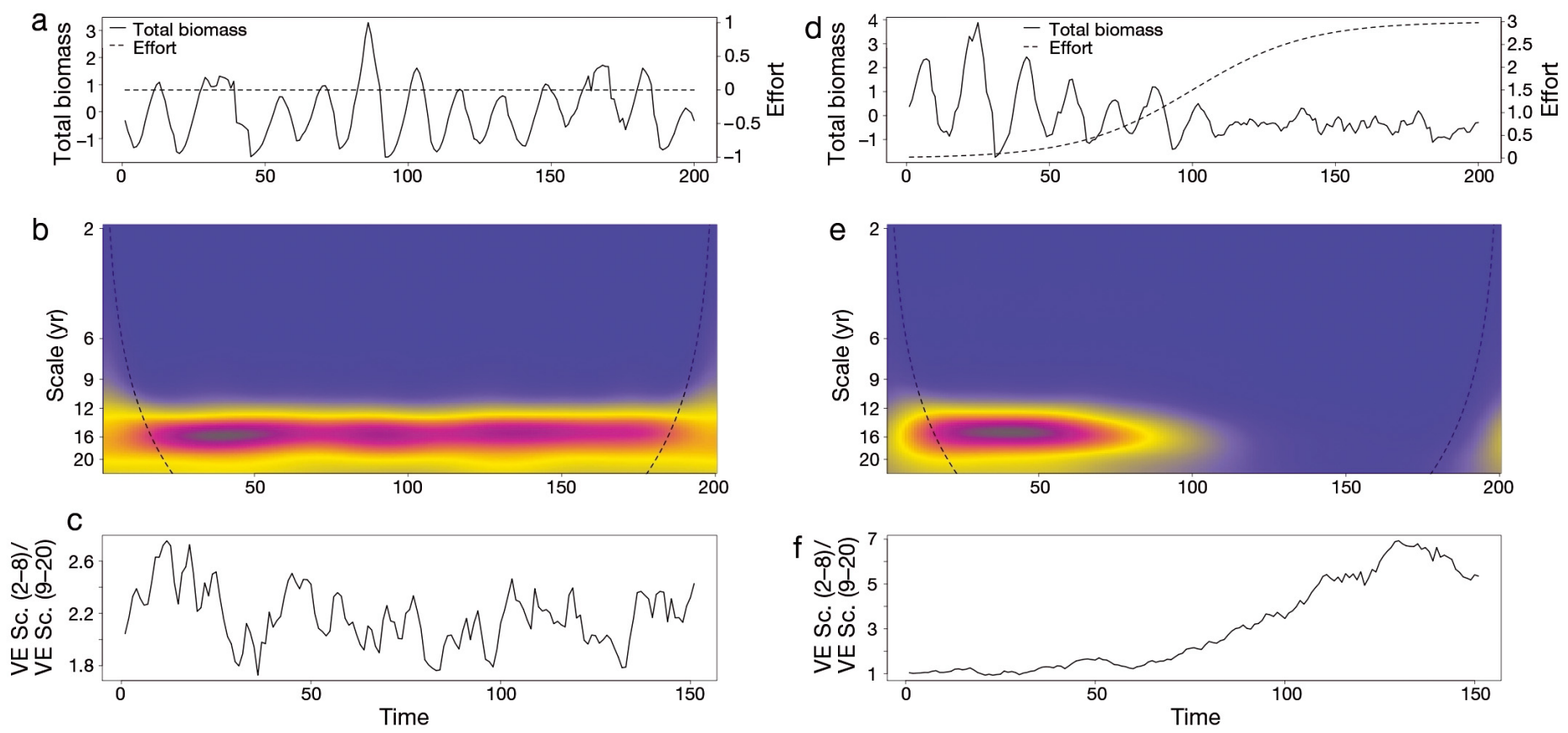

Fig. 7. Population simulations with a red noise environment in the absence of fishing (left panels) and including the fishing effect (right panels). From top to bottom, panels represent $(a, d)$ the total biomass (straight line) and effort (dashed line), (b,e) wavelet spectra (blue-low power values, through dark red to grey-high power values) of total biomass and (c,f) the ratio between the variance explained (VE) by high frequencies ( 2 to $8 \mathrm{yr}$, short time scales) and low frequencies (9 to $20 \mathrm{yr}$, long time scales) of the wavelet spectra. Sc. = scale 

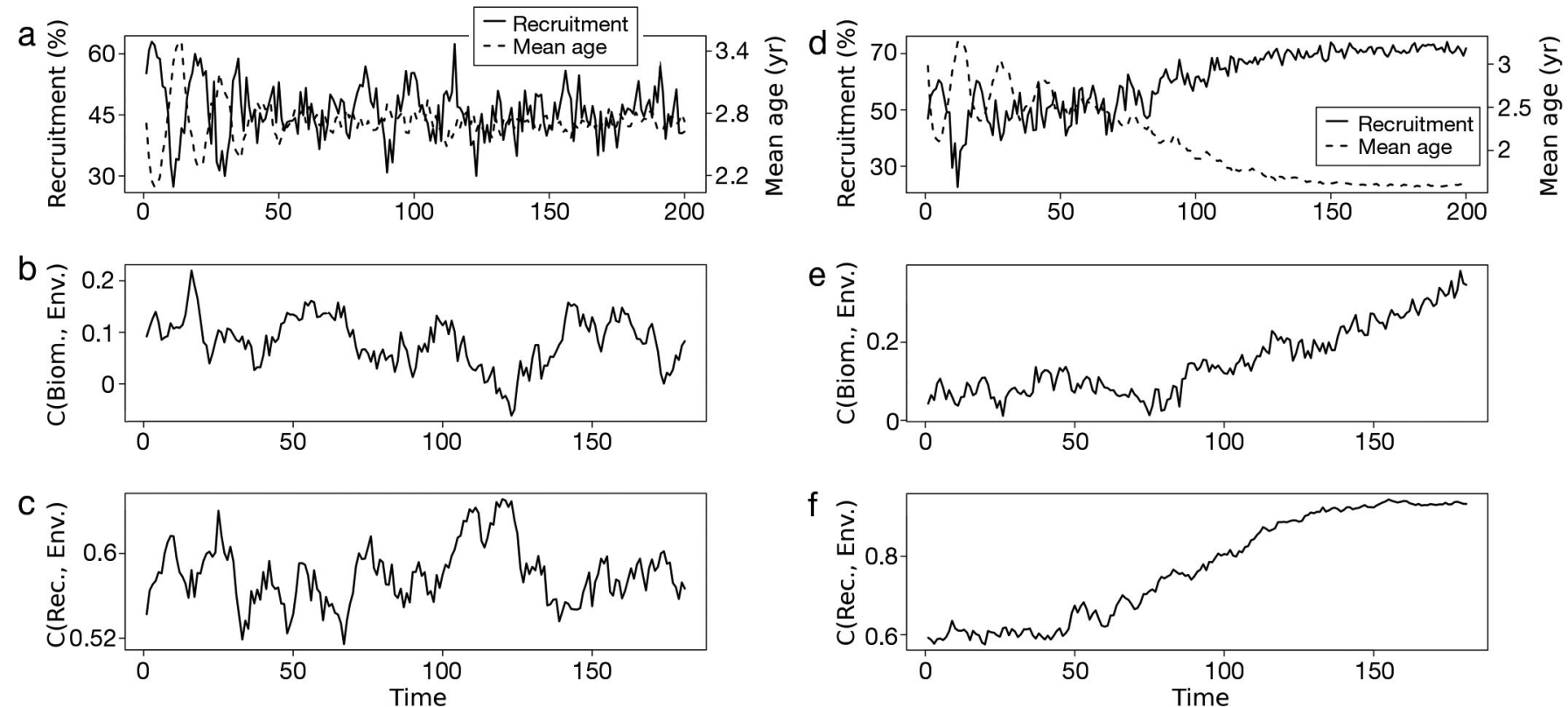

Fig. 8. Population simulation outputs and correlation with the red noise environment in the absence of fishing (left panels) and including the fishing effect (right panels). From top to bottom, panels represent $(a, d)$ the percentage of recruitment in the overall population (straight line) and the mean age (dashed line), (b,e) the correlation between biomass and the environment and (c,f) the correlation between recruitment and the environment. The correlation between time series was obtained on a moving window with a 10 yr span. The correlations were then averaged over 1000 simulations

how fishing, through modification of the age structure, results in the alteration of the cohort resonant effect (Bjørnstad et al. 2004) and therefore the ability of populations to cope with a changing environment. Shifts in the Mediterranean climate along with the selective removal of juveniles have triggered a drastic population change. The long-term exploitation pattern is likely to have eroded the age structure of the population which subsequently became more recruitmentdependent (i.e. juvenescent), and thereby more sensitive to climate variability.

\section{Response of long-term population dynamics to size- selective harvesting}

The simulations of the population dynamics allowed the cyclicity observed in the EH biomass before the 1980s to be reproduced. In our model, such cycles were generated regardless of the environmental scenario (i.e. white and red noise frequencies) through the echoing of stochastic variations in the recruitment over age classes. This is in agreement with findings showing that a population acts as a filter of environmental variations and can magnify stochastic environmental fluctuations at different frequencies (Bjørnstad et al. 1999, 2004, Bjørnstad \& Grenfell 2001). This 'cohortresonance effect' can generate cycles whose proper- ties depend on the life history traits of the species, such as the age at maturity and the age span (Fromentin \& Fonteneau 2001). The periodicity of the cycles produced can therefore be affected by the fishing-induced truncation of the age structure, which affects the characteristics of the filter and those of the internally generated fluctuations. The differences in frequency between the simulated and the observed cycles were then largely due to the assumptions made for the simulations such as: life span, maturity ogive or natural mortality rates. For instance, an increase in natural mortality during early life and juvenile stages due to the increase in intraspecific density-dependent relationships may result in an increase in the frequency of the population cycles. Bjørnstad et al. (2004) and recently Worden et al. (2010) have extensively investigated the complexity of these issues.

The consistency between this hypothesis and the results obtained suggests that fishing exploitation, by altering the demographic structure of $\mathrm{EH}$, has switched the forces shaping the fluctuations from internally generated to externally forced (Fig. 9). Through the changes in the demographic structure, fishing induces a larger dependency on recruitment, accelerates the life cycle and consequently tracks the environment more closely. The 12 yr cycle observed in the biomass index (i.e. CPUE) before the 1980s could have been internally created by density-dependent 


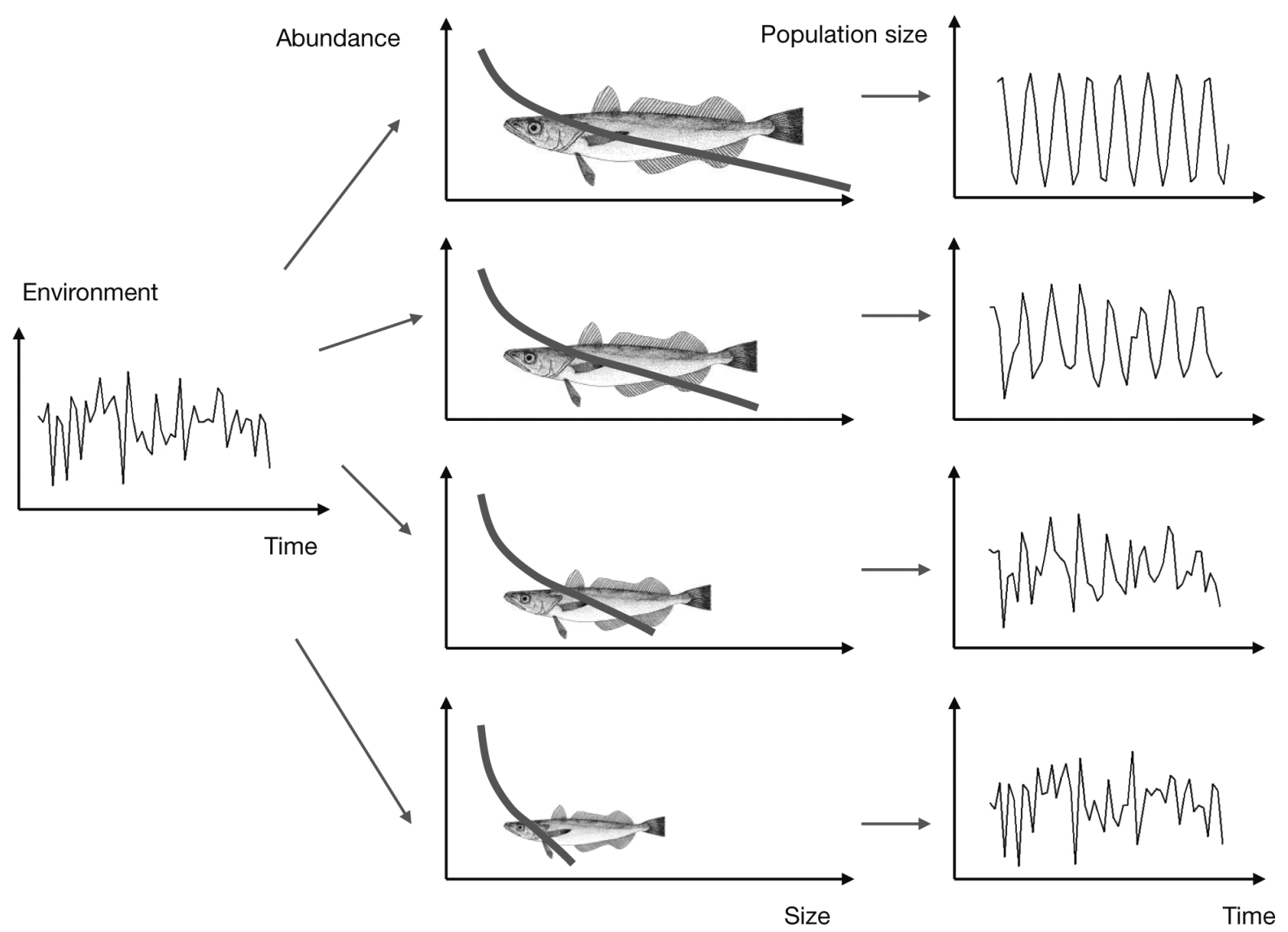

Fig. 9. Schematic representation of the population dynamics consequences on age-structured fish populations under increasing levels of fishery-induced demographic changes and juvenescence. By altering the demographic structure, populations switch from an internally-generated to an externally-forced fluctuation mode, tracking the environmental variability more closely

regulation and the echoing of the environmental disturbances in the age structure through recruitment. Over the last 3 decades (i.e. 1980s, 1990s, 2000s), the $\mathrm{EH}$ population in the Balearic Sea has been shown to depend highly upon recruitment variability (Massutí et al. 2008). The simulations also reproduced this pattern, as they showed an increase in the dependency of the population upon recruitment while exploitation persists. Although Mediterranean fisheries preferentially remove younger age classes ('juvenile fishery', e.g. Caddy 1993, Lleonart \& Maynou 2003), the long-term effect of such an exploitation pattern is comparable to removing older individuals as it removes individuals before they enter the older age classes.

\section{Synergies with the Mediterranean hydroclimatic variability}

Our simulations capture the main long-term features of the observed data (i.e. change in periodicity, sharp depletion of variance, recruitment dependence and increased environmental sensitivity). We acknowledge, however, that the environment could also affect the population at shorter temporal scales (i.e. seasonal) than we simulated. The changes in the inter-annual environmental variability (early 1980s) were linked to a change in the seasonality of the hydroclimate (mainly in the autumn to winter, Fig. 5b). Additionally, the variance of the winter conditions (e.g. IDEA index) increased after the 1980s, displaying a periodic pattern (ca. 6 to 9 yr). Previous studies have shown modifications in the Mediterranean climate through the 1980s and identified drastic changes in the hydroclimatic variables in both the early or/and late 1980s in different areas (e.g. Molinero et al. 2005, Fernández de Puelles \& Molinero 2007, 2008, Conversi et al. 2010). All of these studies attributed these modifications to changes in the North Atlantic climate, which triggered an overall dominance of higher temperatures and atmospheric pressure in the Mediterranean, and weaker wind stress and precipitation.

In oligotrophic systems such as the Mediterranean Sea, the coupling between the phenology (i.e. the tim- 
ing of ecological events) of the biological processes and favourable environmental conditions may be crucial for the persistence of fish populations (Hidalgo et al. 2009b). Since the main spawning season for EH in the NW Mediterranean is autumn (Recasens et al. 1998), the sudden alteration of the seasonality in autumn to winter could likely have lead to a mismatch between egg hatching/early larvae life stages and favourable conditions. Unfortunately, monthly longterm zooplankton time series are not available for the Balearic Islands and therefore we were not able to investigate changes in the coupling between zooplankton density and the early life stages of EH in the early 1980s. However, the clear link observed between zooplankton abundance and hydroclimate from the mid-1990s in the study area (Fernández de Puelles \& Molinero 2007, 2008) indirectly supports our hypothesis. This could have reinforced the patterns reproduced in the simulations and facilitated the drastic change observed in the data. Previous studies on EH in the Balearic system also support this hypothesis, because the drastic depletion of biomass observed in the early 1980s occurred concomitant with the disappearance of the seasonality of the CPUE (Hidalgo et al. 2009a). The erosion of the demographic structure appears to have facilitated the sudden population change in the early 1980s induced by changes in Mediterranean climate, which might affect the trophic interactions of the early life stages of EH.

Finally, the simulations performed illustrate how fishing alters the demographic mechanisms (i.e. quantitative and mathematical) that modulate the population dynamics of age-structured populations. However, these simulations were done assuming constant lifehistory traits while fishing can also affect fish life history, in the short or long term, altering the biological (i.e. qualitative) regulatory responses of individuals within the populations. These responses are, for instance, earlier maturation (Jørgensen et al. 2007 and references therein), increasing somatic growth rate (Jennings et al. 1999, Edeline et al. 2009) or increasing fecundity at a lower age (Trippel et al. 1997). Embracing the consequences of fishing-induced effects on the demography with the changes in life history traits (i.e. 'evolutionary demography', e.g. Coulson et al. 2010) is a future challenge for fisheries ecologists.

\section{CONCLUSIONS AND IMPLICATIONS}

The demographic truncation of fish stocks can also be a qualitative change in their fluctuation, through a modification of the relative importance of both extrinsic and intrinsic factors triggered by exploitation. We stress that the erosion of size structure of harvested populations may drastically alter their ability to filter environmental variability and switch the origin of population fluctuations from internally generated to externally forced. The mechanism we present emphasises that in the Mediterranean ecosystem, where EH exploitation mainly affects juveniles, the inter-annual dynamics of the population are strongly dependent on seasonal processes, more than expected, under a highly recruitment-dependent scenario. Our conclusions highlight the need to consider the interactions between exploitation, climate and internal population properties in management programmes, which has 2 implications. Firstly, the efficiency of the emerging 'ecosystem approach to fisheries' will be undermined if complexity within single harvested populations is not properly implemented. For instance, future research should consider our results in investigations into the consequences of the dynamics of managed pelagic species such as anchovy or horse mackerel on the dynamics of predators such as EH. Secondly, age truncated populations will be difficult to manage because of their high dependence on recruitment, and consequent dependence upon unpredictable environmental variability. Finally, our study underlines that finding significant relationships between recruitment/CPUE time series and environmental conditions is not necessary 'good' news for age-structured populations, because such findings can be a consequence of demographic truncation.

Acknowledgements. We are grateful to J. M. Fromentin, B. Planque and C. H. Hsieh for valuable suggestions on an early version of the manuscript, 3 anonymous referees for their valuable suggestions and $\mathrm{S}$. Hampton for the English revision. M.H. received support from a Marie Curie IntraEuropean fellowship (IEF, FP7-PEOPLE-IEF-2008, European Commission; project EVOLHAKE No 236549). T.R. and N.C.S. acknowledge funding provided by the Norwegian Research Council to the ARCWARM project. E.M., J.M. and B.G. acknowledge funding from the Spanish Ministry of Science and Innovation to the IDEADOS project (CTM200804489-C03-01).

\section{LITERATURE CITED}

Anderson CNK, Hsieh CH, Sandin SA, Hewitt R, Hollowed A, Beddington J, Sugihara G (2008) Why fishing magnifies fluctuations in fish abundance. Nature 452:835-839

Bartolino B (2008) Temporal and spatial dynamics of hake Merluccius merluccius recruitment in the Tyrrhenian and Ligurian Sea (Mediterranean). PhD dissertation, Sapinza University of Rome

Beamish RJ, McFarlane GA, Benson A (2006) Longevity overfishing. Prog Oceanogr 68:289-302

Berkeley SA, Chapman C, Sograd SM (2004a) Maternal age as a determinant of larval growth and survival in a marine fish, Sebastes melanops. Ecology 85:1258-1264

Berkeley SA, Hixon MA, Larson RJ, Love MS (2004b) Fish- 
eries sustainability via protection of age structure and spatial distribution of fish populations. Fisheries 29:23-32

Bjørnstad ON, Grenfell BT (2001) Noisy clockwork: time series analysis of population fluctuations in animals. Science 293:638-643

Bjørnstad ON, Fromentin JM, Stenseth NC, Gjøsæter J (1999) Cycles and trends in cod populations. Proc Natl Acad Sci USA 96:5066-5071

Bjørnstad ON, Nisbet RM, Fromentin JM (2004) Trends and cohort resonant effects in age-structured populations. J Anim Ecol 73:1157-1167

Brunel T (2010) Age-structure-dependent recruitment: a meta-analysis applied to Northeast Atlantic fish stocks. ICES J Mar Sci 67:1921-1930

Caddy JF (1993) Some future perspectives for assessment and management of Mediterranean fisheries. Sci Mar 57: $121-130$

Caddy JF, Abella AJ (1999) Reconstructing reciprocal M vectors from length cohort analysis (LCA) of commercial size frequencies of hake, and fine mesh trawl surveys over the same grounds. Fish Res 41:169-175

> Cazelles B, Chavez M, Berteaux D, Menard F, Vik JO, Jenouvrier S, Stenseth NC (2008) Wavelet analysis of ecological time series. Oecologia 156:287-304

Clarke KR, Warwick RM (1994) Change in marine communities. Plymouth Marine Laboratory, Plymouth

> Conversi A, Fonda Umani S, Peluso T, Molinero JC, Santojanni A, Edwards M (2010) The Mediterranean sea regime shift at the end of the 1980s, and intriguing parallelisms with other European basins. PLoS ONE 5:e10633

Coulson T, Tuljapurkar S, Childs DZ (2010) Using evolutionary demography to link life history theory, quantitative genetics and population ecology. J Anim Ecol 79: $1226-1240$

Edeline E, Le Rouzic A, Winfield IJ, Fletcher JM, James JB, Stenseth NC, Vøllestad LA (2009) Harvest-induced disruptive selection increases variance in fitness-related traits. Proc R Soc B Biol Sci 276:4163-4171

FAO-GFCM (FAO-General Fisheries Commission for the Mediterranean) (2008) Report of the tenth session of the Scientific Advisory Committee. Nicosia, Cyprus, 22-26 October 2007. FAO Fisheries Report, No 856. FAO, Rome

Fernández de Puelles ML, Molinero JC (2007) North Atlantic climate control on plankton variability in the Balearic Sea, western Mediterranean. Geophys Res Lett 34:L04608 doi: 10.1029/2006GL028354

Fernández de Puelles ML, Molinero JC (2008) Decadal changes in hydrographic and ecological time-series in the Balearic Sea (western Mediterranean), identifying links between climate and zooplankton. ICES J Mar Sci 65:311-317

Fromentin JM, Fonteneau A (2001) Fishing effects and life history traits: a case study comparing tropical versus temperate tunas. Fish Res 53:133-150

Hidalgo M, Massutí E, Moranta J, Cartes JE, Lloret J, Oliver P, Morales-Nin B (2008) Seasonal and short spatial patterns in European hake (Merluccius merluccius L.) recruitment process at the Balearic Islands (western Mediterranean): the role of environment on distribution and condition. J Mar Syst 71:367-384

Hidalgo M, Massutí E, Guijarro B, Moranta J and others (2009a) Population effects and changes in life-history traits in relation to phase transitions induced by long-term fishery harvesting: European hake off the Balearic Islands. Can J Fish Aquat Sci 66:1355-1370

- Hidalgo M, Tomás J, Moranta J, Morales-Nin B (2009b) Intraannual recruitment events of a shelf species around an island system in the NW Mediterranean. Estuar Coast Shelf Sci 83:227-238

- Hsieh CH, Reiss CS, Hunter JR, Beddington JR, May RM, Sugihara G (2006) Fishing elevates variability in the abundance of exploited species. Nature 443:859-862

Hsieh CH, Yamauchi A, Nakazawa T, Wang WF (2010) Fishing effects on age and spatial structures undermine population stability of fishes. Aquat Sci 72:165-178

Hutchings JA, Reynolds JD (2004) Marine fish population collapses: consequences for recovery and extinction risk. Bioscience 54:297-309

Jennings S, Greenstreet SPR, Reynolds JD (1999) Structural changes in an exploited fish community: a consequence of differential fishing effects on species with contrasting life histories. J Anim Ecol 68:617-627

Jørgensen C, Enberg K, Dunlop E, Arlinghaus R and others (2007) Managing evolving fish stocks. Science 318: $1247-1248$

Kalnay E, Kanamitsua M, Kistlera R, Collins W and others (1996) The NCEP/NCAR 40-year reanalysis project. Bull Am Meteorol Soc 77:437-471

Kirby R, Beaugrand G, Lindley JA (2009) Synergistic effects of climate and fishing in a marine ecosystem. Ecosystems 12:548-561

Lleonart J, Maynou F (2003) Fish stock assessments in the Mediterranean: state of the art. Sci Mar 67:37-49

Longhurst AR (ed) (1998) Ecological geography of the sea. Academic Press, London

> Massutí E, Monserrat S, Oliver P, Moranta J and others (2008) The influence of oceanographic scenarios on the population dynamics of demersal resources in the western Mediterranean: hypotheses for hake and red shrimp off the Balearic Islands. J Mar Syst 71:421-438

> Menard F, Marsac F, Bellier E, Cazelles B (2007) Climatic oscillations and tuna catch rates in the Indian Ocean: a wavelet approach to time series analysis. Fish Oceanogr 16:95-104

> Molinero JC, Ibanez F, Nival P, Buecher E, Souissi S (2005) North Atlantic climate and northwestern Mediterranean plankton variability. Limnol Oceanogr 50:1213-1220

> Monserrat S, Marcos M, López-Jurado J (2008) Interannual variability of Winter Intermediate Water at the Balearic Islands. J Mar Syst 71:413-420

Oliver P (1993) Analysis of fluctuations observed in the trawl net fleet landings of the Balearic Islands. Sci Mar 57: $219-227$

Ottersen G (2008) Pronounced long-term juvenation in the spawning stock of Arcto-Norwegian cod and possible consequences for recruitment. Can J Fish Aquat Sci 65: 523-534

> Ottersen G, Hjermann DO, Stenseth NC (2006) Changes in spawning stock structure strengthen the link between climate and recruitment in a heavily fished cod (Gadus morhua) stock. Fish Oceanogr 15:230-243

> Perry RI, Cury P, Brander K, Jennings S, Möllmann C, Planque B (2010) Sensitivity of marine systems to climate and fishing: concepts, issues and management responses. J Mar Syst 79:427-435

Planque B, Fromentin JM, Cury P, Drinkwater KF, Jennings S, Perry I, Kifani S (2010) How does fishing alter marine populations and ecosystems sensitivity to climate? J Mar Syst 79:403-417

- Pyper B, Peterman B (1998) Comparison of methods to account for autocorrelation in correlation analyses of fish data. Can J Fish Aquat Sci 55:2127-2140

Recasens L, Lombarte A, Morales-Nin B, Torres GJ (1998) 
Spatio-temporal variation in the population structure of the European hake in the NW Mediterranean. J Fish Biol 53:387-401

Rouyer T, Fromentin JM, Menard F, Calzelles B and others (2008) Complex interplays among population dynamics, environmental forcing, and exploitation in fisheries. Proc Natl Acad Sci USA 105:5420-5425

Stenseth NC, Rouyer T (2008) Destabilized fish stocks. Nature 452:825-826

Trippel EA, Kjesbu OS, Solemdal P (1997) Effects of adult age and size structure on reproductive output in marine fishes.

Editorial responsibility: Konstantinos Stergiou,

Thessaloniki, Greece
In: Chambers RC, Trippel EA (eds) Early life history and recruitment in fish populations. Chapman and Hall, London, p 31-62

Vasseur DA, Yodzis P (2004) The color of environmental noise. Ecology 85:1146-1152

Walsh MR, Munch SB, Chiba S, Conover DO (2006) Maladaptive changes in multiple traits caused by fishing: impediments to population recovery. Ecol Lett 9:142-148

> Worden L, Botsford LW, Hastings A, Holland MD (2010) Frequency responses of age-structured populations: Pacific salmon as an example. Theor Popul Biol 78:239-249

Submitted: September 30, 2010; Accepted: February 9, 2011 Proofs received from author(s): March 15, 2011 